\title{
Contribution of SecDF to Staphylococcus aureus resistance and expression of virulence factors
}

\author{
Chantal Quiblier ${ }^{1}$, Annelies S Zinkernagel ${ }^{2}$, Reto A Schuepbach ${ }^{3}$, Brigitte Berger-Bächi ${ }^{1}$ and Maria M Senn ${ }^{1 *}$
}

\begin{abstract}
Background: SecDF is an accessory factor of the conserved Sec protein translocation machinery and belongs to the resistance-nodulation-cell division (RND) family of multidrug exporters. SecDF has been shown in Escherichia coli and Bacillus subtilis to be involved in the export of proteins. RND proteins can mediate resistance against various substances and might be of relevance in antimicrobial therapy. The role of RND proteins in Staphylococcus aureus has not yet been determined.

Results: Markerless deletion mutants were constructed to analyze the impact of the so far uncharacterized RND proteins in S. aureus. While the lack of Sa2056 and Sa2339 caused no phenotype regarding growth and resistance, the secDF mutant resulted in a pleiotropic phenotype. The secDF mutant was cold sensitive, but grew normally in rich medium at $37^{\circ} \mathrm{C}$. Resistance to beta-lactams, glycopeptides and the RND substrates acriflavine, ethidium bromide and sodium dodecyl sulfate was reduced. The secDF mutant showed an aberrant cell separation and increased spontaneous and Triton X-100 induced autolysis, although the amounts of penicillin-binding proteins in the membrane were unchanged. The impact of secDF deletion on transcription and expression of specific virulence determinants varied: While coagulase transcription and activity were reduced, the opposite was observed for the autolysin Atl. A reduction of the transcription of the cell wall anchored protein A (spa) was also found. The accumulation of SpA in the membrane and lowered amounts in the cell wall pointed to an impaired translocation.

Conclusions: The combination of different effects of secDF deletion on transcription, regulation and translocation lead to impaired cell division, reduced resistance and altered expression of virulence determinants suggesting SecDF to be of major relevance in S. aureus. Thus SecDF could be a potential target for the control and eradication of $S$. aureus in the future.
\end{abstract}

\section{Background}

Staphylococcus aureus is a frequent colonizer of the human body as well as a serious human pathogen. It is known for its adaptability to diverse environments. It can cope with stress factors and acquire resistances to antibiotics thus rendering treatment difficult. S. aureus can cause a wide range of infections, mainly due to an impressive arsenal of virulence determinants comprising cell surface components and excreted factors interacting with the host system. Transport of proteins to the cell surface and secretion to the extracellular space is mediated through different transport systems [1] of which the general protein secretion system Sec plays a

\footnotetext{
* Correspondence: msenn@imm.uzh.ch

${ }^{1}$ Institute of Medical Microbiology, University of Zurich, Gloriastr. 32, 8006

Zurich, Switzerland

Full list of author information is available at the end of the article
}

prominent role in protein export and membrane insertion.

Sec-mediated translocation has best been studied in Escherichia coli and is catalyzed by the essential SecYEG protein complex (reviewed in [2]). The motor ATPase SecA or a translating ribosome is believed to promote protein export by driving the substrate in an unfolded conformation through the SecYEG channel. The accessory SecDF-YajC complex facilitates protein export and membrane protein insertion efficiency in vivo [3], possibly via the control of SecA cycling [4]. The large exoplasmic loops of the integral membrane proteins SecD and SecF have been shown to be required for increasing protein translocation by a yet unknown mode of action [5]. While $\sec D F$ disruption leads to a cold-sensitive phenotype and defects in protein translocation [6], the absence of YajC, which interacts with SecDF, causes 
only a weak phenotype [7]. SecYEG has been shown to interact with the SecDF-YajC complex [8]. YidC, a protein that is proposed to mediate membrane integration and the assembly of multimeric complexes, can also interact with SecDF-YajC to take over SecYEG-dependent membrane proteins [9].

Data on the $S$. aureus Sec system is scarce: SecA and SecY have been shown to be important, respectively essential, for growth by using antisense RNA [10]. Deletion of $\sec G$ resulted in an altered composition of the extracellular proteome, which was aggravated in a $\sec G$ $\sec Y 2$ double mutant [11]. Deletion of secY2 alone, which together with secA2 belongs to the accessory Sec system [12], did not show any effect on protein translocation. As in the Gram-positive bacterium Bacillus subtilis, in S. aureus the accessory SecD and SecF proteins are fused to form a single protein (Sa1463), which was identified in membrane vesicles [13]. However, the chromosomal organization in $S$. aureus resembles the one of E. coli, with yajC lying immediately upstream of $\sec D F$. Furthermore, SecDF was identified in a surface-exposed peptide epitope screen by using a cell shaving technique [14] and expression was found to be slightly higher in a COL $\operatorname{sig} B$ deletion mutant [15]. SecDF is postulated to be essential in $S$. aureus according to a mutagenic screen [16].

SecDF belongs to the resistance-nodulation-cell division (RND) family of multidrug export pumps, that is conserved and widely distributed in all three major kingdoms of life [17]. RND proteins have a wide substrate specificity and diverse functions ranging from the efflux of noxious host derived substances, such as bile salts by E. coli [18] to the involvement of eukaryotic efflux pumps in cholesterol homeostasis in humans [19]. Multiple antibiotic resistance can be associated with these exporters, as they often recognize a broad range of substrates, thereby diminishing drug accumulation in the cell $[20,21]$. S. aureus possesses two additional uncharacterized RND proteins, namely Sa2056, located downstream of the essential femX [22], and Sa2339 (MmpL homologue).

\section{Results}

\section{Construction of the rnd mutants}

To evaluate the role and impact of the RND proteins in S. aureus, markerless deletion mutants were constructed in the sequenced and well-characterized clinical strain Newman. SecDF, Sa2056 and Sa2339 were found to be dispensable, as we obtained null mutants by allelic replacement of the corresponding genes using the pKOR1 system of Bae et al. [23]. The mutants were confirmed to have generally retained genome stability and to carry the desired modification in the corresponding locus as described in methods.
Deletion of sa2056 and sa2339 had no apparent effect on $S$. aureus when evaluating growth and resistance properties (data not shown), suggesting that they may be important under other conditions than applied in this study. The following report is therefore focused on the $\sec D F$ mutant and its phenotype.

\section{Transcription of secDF and growth phenotype of the secDF mutant}

Transcription of secDF was monitored from early exponential to early stationary phase and found to result mainly in a monocistronic mRNA. secDF was strongest transcribed during early growth phase and declined towards stationary phase (Figure 1A). As expected, no transcripts were detected in the secDF deletion mutant. Transcriptional profiles were restored in the mutant by introducing the complementing plasmid $\mathrm{pCQ} 27$, containing the $\sec D F$ gene from Newman with its endogenous promoter (data not shown).

At $37^{\circ} \mathrm{C}$ no significant difference was observed when comparing the growth curves of the wild type strain Newman and the mutant (Figure 1B). However, colonies of secDF mutants were smaller on blood agar compared to the wild type $(83 \% \pm 5.1$ of the wild type's cross section). TEM pictures were prepared from exponentially growing cells. In contrast to the wild type (Figure $2 \mathrm{~A}$ ) and the complemented mutant (Figure 2C), displaying normally shaped cells with a maximum of one septum, the secDF mutant had difficulties in separating daughter cells (Figure 2B and 2D). This resulted in clusters with sometimes multiple and wrongly placed septa. At least 400 cells per strain were analyzed, showing that $20.4 \pm$ $8.7 \%$ of the mutant cells could not divide correctly whereas this was only the case in $0.3 \pm 0.7 \%$ for the wild type and $0.9 \pm 1.3 \%$ for the complemented mutant.

As secDF knock out mutants in B. subtilis and E. coli show a cold sensitive phenotype $[6,24]$, growth of the $S$. aureus secDF mutant was tested at $15^{\circ} \mathrm{C}$. The temperature drop affected the $s e c D F$ mutant approximately after two generations, causing a notably reduced growth rate with a subsequent halt in growth after $24 \mathrm{~h}$. The plasmid $\mathrm{pCQ} 27$, but not the empty vector $\mathrm{pCN} 34$, significantly restored growth at $15^{\circ} \mathrm{C}$ (Figure $1 \mathrm{~B}$ ).

\section{Increased susceptibility of the secDF mutant towards RND-substrates, $\beta$-lactam and glycopeptide antibiotics}

Since multidrug resistance can be mediated unspecifically by RND exporters [21,25], we characterized the resistance profile of the $\sec D F$ mutant by testing several different classes of antibiotics and typical RND-substrates [26,27]. The secDF mutant showed increased susceptibility to the RND substrates acriflavine, ethidium bromide and sodium dodecyl sulfate (SDS) on gradient plates (Figure 3). Furthermore, a distinct increased 

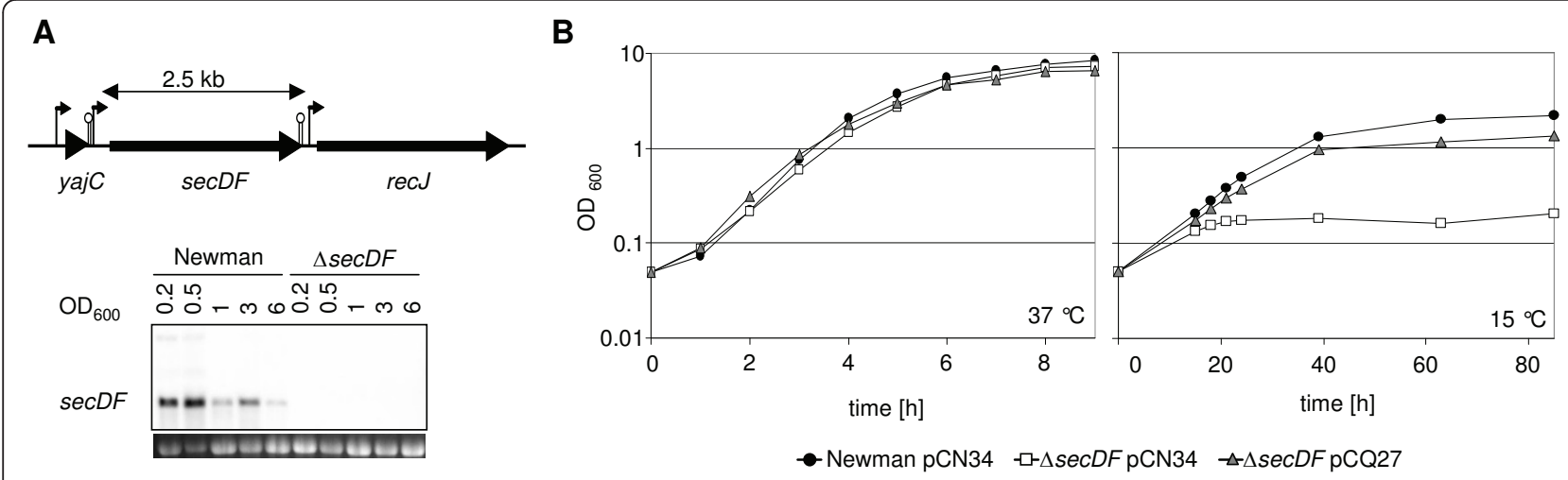

Figure 1 Growth characteristics of the secDF mutant. (A) Genetic context of secDF in S. aureus and Northern blot analysis of secDF transcription during growth. Predicted promoter and terminators are depicted. Ethidium bromide-stained 16S rRNA is shown as an indication of RNA loading. (B) Growth of Newman and the secDF mutant carrying the empty vector pCN34, and of the complemented mutant secDF pCQ27 in $\mathrm{LB}$ broth at $37^{\circ} \mathrm{C}$ and $15^{\circ} \mathrm{C}$, respectively.

susceptibility to the $\beta$-lactam oxacillin and the glycopeptide vancomycin was observed (Figure 3). The reduction of oxacillin resistance was even more apparent in the presence of $m e c A$, the gene encoding the penicillin binding protein $2 \mathrm{a}$ (PBP2a), mediating methicillin resistance, as shown for the methicillin resistant $S$. aureus (MRSA) strain pair Newman pME2 and Newman secDF pME2 (Figure 3) [28]. Reduction of oxacillin resistance in MRSA by secDF inactivation was confirmed in strains of different genetic backgrounds or SCCmec types, such as the clinical isolate CHE482 [29] and RA2 [30] or RA120 [31] (data not shown). The complementing

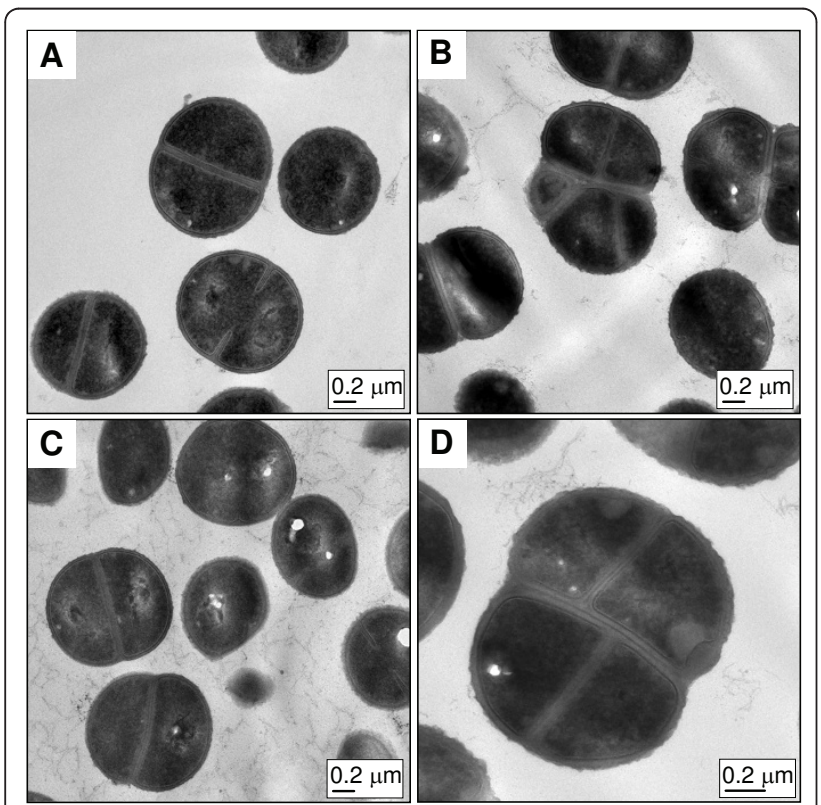

Figure 2 Cell morphology. TEM pictures from thin sections of strains (A) Newman pCN34, (B and D) $\triangle \operatorname{secDF}$ pCN34 and (C) $\triangle$ secDF pCQ27 during exponential phase $\left(\mathrm{OD}_{600} 0.5\right)$. plasmid pCQ27 was able to restore the wild type resistance levels.

Of the four endogenous S. aureus PBPs, PBP1 and PBP2 are essential, and reducing their expression lowers methicillin resistance even in the presence of the low $\beta$ lactam affinity PBP2a in MRSA [32,33]. As the Sec-system can promote protein insertion into the cytoplasmic membrane, we determined whether the reduced oxacillin resistance of the $\sec D F$ mutant may be related to altered PBP amounts and/or subcellular localization. Staining cell membranes with the fluorescent penicillinderivative Bocillin-FL [34] showed no major difference of PBP1-3 content in wild type MRSA background or corresponding secDF mutants (Figure 4A). However, Bocillin-FL staining did not allow the detection of the Sec-type signal peptide containing PBP4 [1] of approximately $48 \mathrm{kDa}$, or to distinguish the exogenous PBP2a in the Newman background (Figure 4A and 4B), possibly due to low protein levels or overlap, respectively. Western blots revealed comparable PBP2a and PBP4 amounts in the membrane fraction throughout growth, irrespective of the presence of SecDF (Figure 4B).

\section{Increased autolysis and hydrolysis in the secDF mutant}

Apart from functional PBPs, correct separation of daughter cells requires the controlled action of autolysins and hydrolases, many of which are Sec-dependent [1]. We therefore tested spontaneous and Triton X-100 induced autolysis to determine if the inability of $\sec D F$ mutants to separate correctly was due to altered expression of autolytic activities. Both, spontaneous and Triton $\mathrm{X}-100$ induced autolysis of the $\sec D F$ mutant were increased in comparison to the wild type or the complemented mutant (Figure 5A).

To determine whether wild type and mutant bacteria produced different levels of hydrolases, their activity was 
A

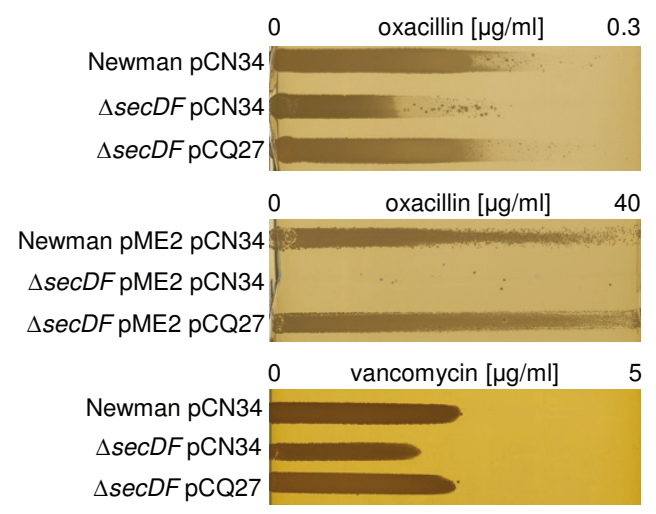

B

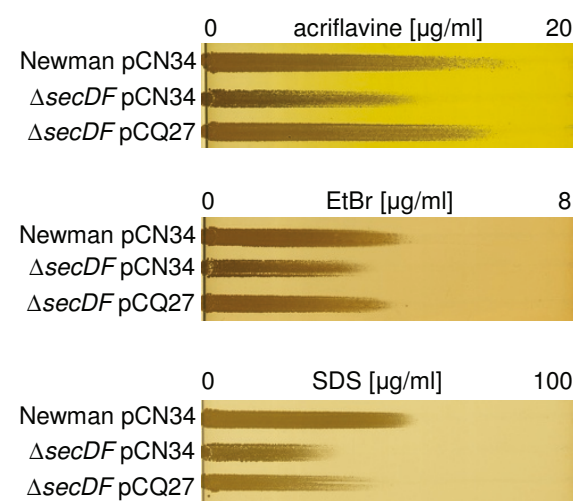

Figure 3 Effect of secDF inactivation on resistance profiles. (A) Gradient plates with increasing concentrations of $\beta$-lactam and glycopeptide antibiotics. Oxacillin was tested with methicillin sensitive and methicillin resistant strain Newman, the latter carrying the plasmid pME2 containing the mecA gene. (B) Gradient plates with increasing concentrations of the RND substrates acriflavine, ethidium bromide and SDS.

analyzed in concentrated supernatant and cell wall extracts (Figure 5B). In the supernatant of the mutant, high molecular mass bands matching different forms of the major $S$. aureus autolysin Atl [35], were expressed similarly $(>130 \mathrm{kDa}$, pro-Atl) or even stronger

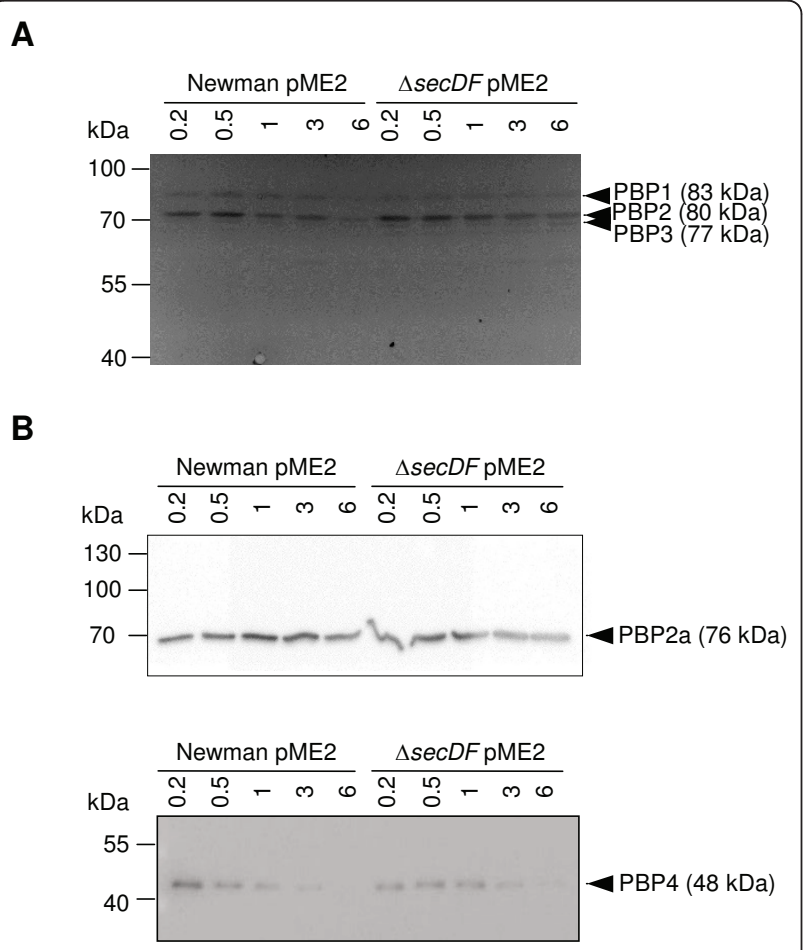

Figure 4 PBP expression over growth. Strain Newman pME2, carrying $m e c A$, and its secDF mutant were cultivated in $L B$ and samples collected at the indicated $\mathrm{OD}_{600}$ were used to prepare membrane fractions. (A) Membranes were incubated with the fluorescent penicillin analogue Bocillin-FL. Bands corresponding to PBPs 1-3 are indicated. (B) Western blot analysis of membrane fractions using antibodies against PBP2a and PBP4, respectively.
( $84 \mathrm{kDa}, \mathrm{PP}-\mathrm{AM})$ compared to the wild type and the complemented mutant (Figure 5B). Interestingly, the $>130 \mathrm{kDa}$ band migrated at a slightly higher position in the mutant, corresponding to the height of the pro-Atl band in the cell wall fractions, where the mutant showed overall stronger hydrolytic bands than wild type or complemented mutant.

\section{Deletion of secDF leads to altered expression of virulence factors}

We qualitatively assessed the amount of various Secdependent $S$. aureus virulence factors, such as coagulase, hemolysin and protease activities, as well as of the immunomodulatory protein SpA to determine whether they were affected in the $\sec D F$ mutant as well.

Supernatant from Newman and the complemented secDF mutant coagulated rabbit plasma after $30 \mathrm{~min}$, whereas the $\sec D F$ mutant required $90 \mathrm{~min}$, suggesting production of slightly reduced coagulase levels. Extracellular proteolytic activity seemed to be absent in the secDF mutant, even after five days of incubation, whereas cultures from Newman and the complemented mutant showed distinct proteolytic halos on skim milk agar after $72 \mathrm{~h}$ (Figure 6A). Hemolysis activity was tested by a similar agar diffusion assay as used for protease activity determination. Overnight cultures, or sterile-filtrated culture supernatants, were dispensed into holes on sheep blood agar. Newman and the complemented secDF mutant showed the same extent of hemolysis. In the secDF background hemolysis was reduced when bacteria grew on the rim of agar holes (Figure $6 \mathrm{~B})$, but was increased when the hemolytic activity of sterile supernatant from liquid cultures was tested (Figure $6 \mathrm{C}$ and $6 \mathrm{D}$ ). Sessile or planktonic growth affects regulatory mechanisms, which can alter the expression 
A

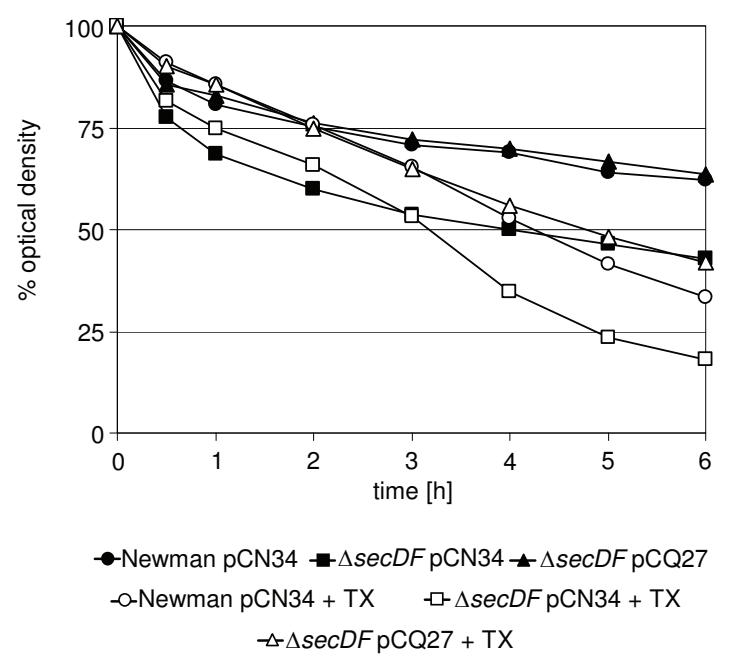

B

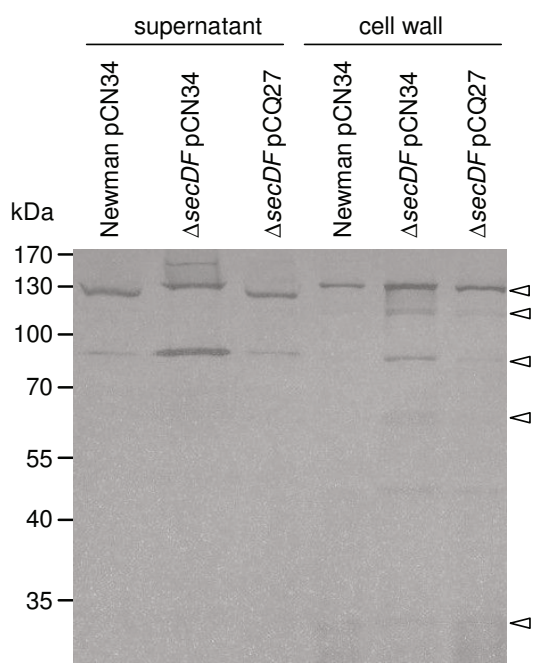

Figure 5 Autolysis and zymogram. (A) Spontaneous and Triton X-100 (TX) induced autolysis was measured over time. (B) Autolysin zymography of protein extracts from supernatant and cell wall was performed using SDS-10\% PAGE supplemented with S. aureus cell wall extract as a substrate. Dark bands show hydrolyzed cell wall and are indicated by triangles. Based on the work of Schlag et al. bands were assigned as follows in decreasing order: Pro-Atl ( 130 kDa); Atl ( 115 kDa); Atl-amidase ( 84 kDa) or part of the propeptide (62-65 kDa); Sle1/Aaa $(\sim 33 \mathrm{kDa})[35]$.

of virulence factors such as Hla [36,37]. Here we found that the deletion of secDF had divergent effects on hemolysin expression depending on the growth conditions, most likely by affecting regulatory processes.

$\mathrm{SpA}$ is one of the proteins predicted to be attached to the cell wall by sortase following export [38]. SpA levels were determined in subcellular fractions during growth by Western blot analyses.
Compared to the wild type, SpA levels were reduced in the cell wall and the cytoplasmic fraction, but slightly increased in the cell membrane fraction of the secDF mutant (Figure 7). The SpA levels were similar in the supernatant. Processed SpA has a molecular weight of approximately $51 \mathrm{kDa}$ in strain Newman as estimated by Western blot analysis of wild type and $\Delta s p a$ protein extracts (Additional file 1: Figure S1). Larger bands

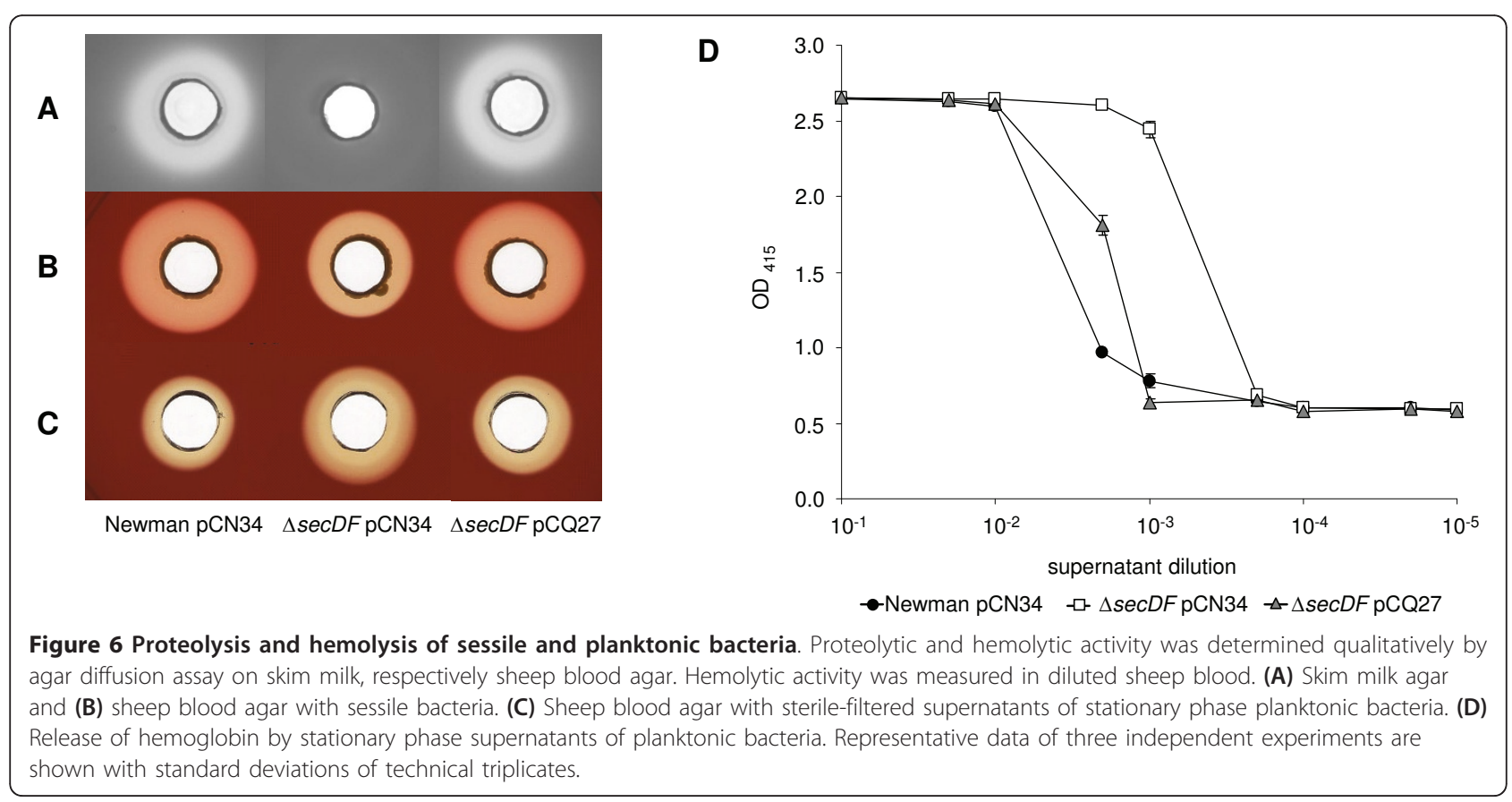




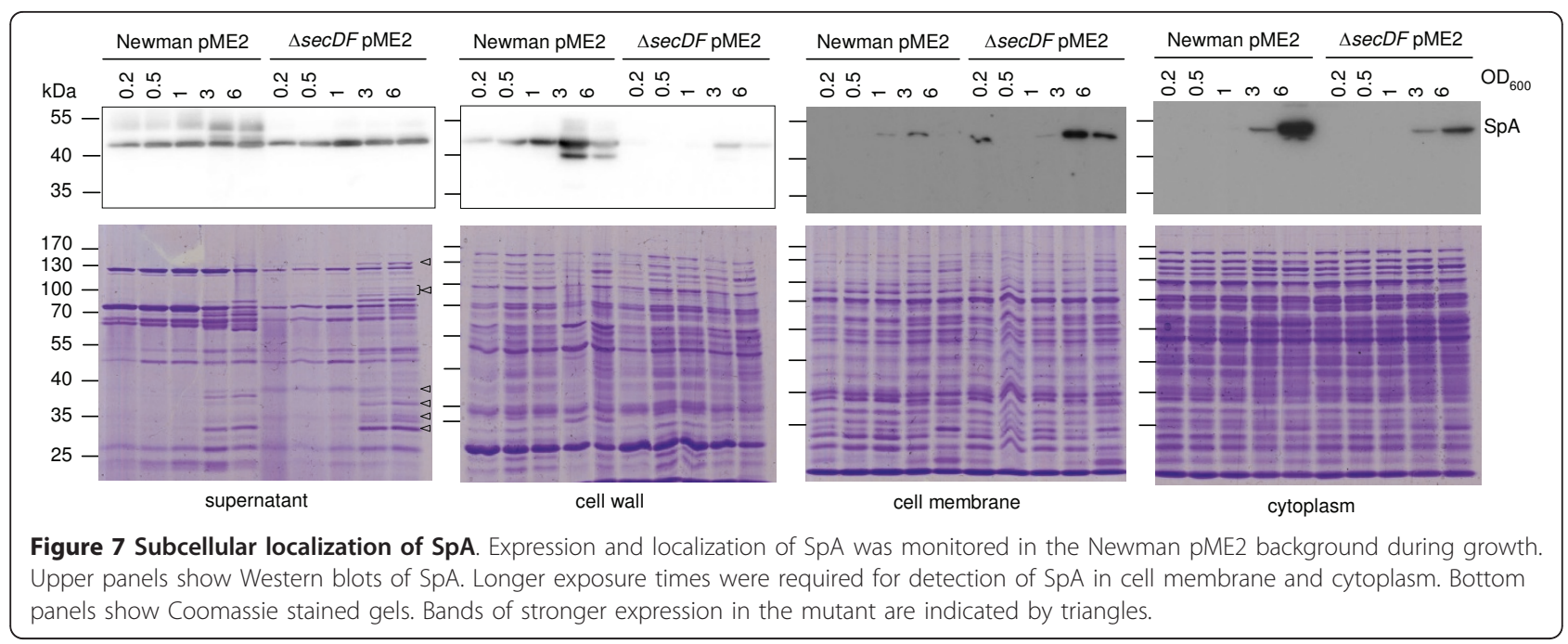

( $\sim 53 \mathrm{kDa})$ in the wild type supernatant fraction most likely represent $\mathrm{SpA}$ still attached to cell wall fragments. Thus, SpA translocation and/or processing seemed to be affected by the $\sec D F$ deletion, a phenotype that could be complemented by introducing PCQ27 (data not shown).

Surprisingly, secreted SpA amounts were fairly constant despite this translocation defect. Also in the wild type, SpA levels in the supernatant were constant, whereas the amount of cell wall-bound SpA increased during growth, suggesting constant shedding of this protein.

\section{Transcriptional analyses of virulence factors reveal regulatory changes in the secDF mutant}

To determine whether the altered protein levels in the secDF mutant reflected also the mRNA level, transcription of atl $(\sim 3.8 \mathrm{~kb})$, coa $(\sim 1.9 \mathrm{~kb})$, hla $(\sim 1 \mathrm{~kb})$ hld $(\sim 0.5 \mathrm{~kb})$ and spa $(\sim 1.6 \mathrm{~kb})$ were examined at different growth phases. atl transcription was elevated in the mutant during the entire growth (Figure 8 ) which is in agreement with the increased hydrolytic activities observed (Figure 5B). Transcription of coa sharply decreased after $\mathrm{OD}_{600}$ of 1 . Slightly lower transcription levels were seen for coa in the secDF mutant (Figure 8), which is in line with our findings for its coagulation properties. As Newman carries a prophage in the $h l b$ gene [39] and the gamma toxin is inhibited by sulfonated polymers in agar [40], we only looked at the transcription of the genes encoding $\alpha$ and $\delta$ toxins. hla amounts in the mutant were reduced compared to the wild type (Figure 8). The transcription pattern of hld, contained in the major regulatory RNAIII, had a tendency to being slightly reduced in the mutant but still showed a growth phase dependent expression, starting at $\mathrm{OD}_{600} 3$ (Figure 8, data was assessed for the relevant
ODs 1, 3 and 6). A striking difference was observed for the spa transcription, which in the wild type increased over growth with a peak at $\mathrm{OD}_{600} 3$, but was drastically reduced in the secDF mutant (Figure 8). These findings were in contrast to the observed higher hemolytic activities and SpA amounts in the supernatant (Figure 6 respectively 7), which either suggests increased stability or reduced degradation of these proteins in the secDF mutant.

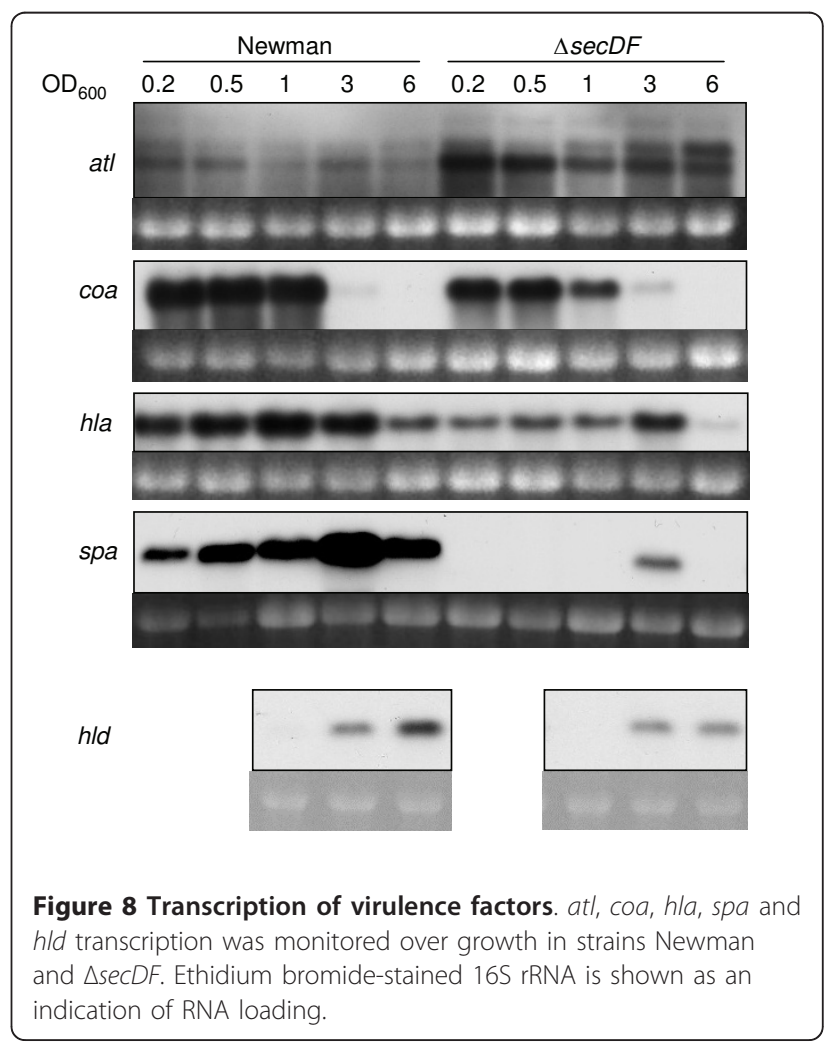




\section{Discussion}

Efflux pumps play an important role in S. aureus resistance, virulence and pathogenicity. Yet the impact of the RND family of efflux pumps in staphylococcal resistance and fitness is still open (reviewed in [41]). To our knowledge, this is the first study to evaluate their role in S. aureus.

We found SecDF to contribute probably in part indirectly to resistance against several substances, including $\beta$-lactams and glycopeptides, making it an interesting target for increasing the efficacy of these standard antibiotics. In contrast Sa2056 and Sa2339 seemed not to be required for growth and resistance under the conditions tested. Banerjee et al. recently had found a conservative amino acid mutation in Sa2056 in a high-level $\beta$-lactam resistant $m e c A$-negative strain [42]. However in that strain PBP4 and Sa0013 were also mutated and the exact reason for the observed resistance phenotype was not identified.

Resistance against cell wall active antibiotics and cell separation is dependent on a tightly balanced regulation of cell wall synthetic and hydrolytic enzymes, including their timely localization to the septum $[43,44]$. The amount of PBPs $1-4$ and PBP2a was apparently not influenced, suggesting that other factors important for cell division and $\beta$-lactam resistance were affected. The increased hydrolytic activity in the secDF mutant may explain the observed differences in cell wall production and separation. Overproduction of a hydrolase has been observed to affect formation of the FtsZ-ring in Mycobacterium tuberculosis [45]. This cytoskeleton structure recruits the other cell division proteins to the site of future cell separation. A similar indirect effect in the secDF mutant might have lead to an incorrect localization of the cell division machinery, including PBPs (for a general review see [46]), thereby causing reduced resistance against the cell wall active antibiotics oxacillin and vancomycin. The difference in Atl processing might have impeded proper cell separation in addition.

Like $E$. coli and B. subtilis secDF mutants [6,24], the $S$. aureus secDF mutant displayed a cold-sensitive phenotype. In E. coli and B. subtilis SecDF has furthermore been shown to participate in membrane integration and secretion of proteins $[6,24,47]$. In $S$. aureus many physiological functions were affected by the secDF deletion. Analysis of the secretion of classical $S$. aureus virulence factors containing a Sec-type signal peptide revealed a complex picture. Coagulase and proteases were reduced in the supernatant in the secDF mutant. However, hemolysin activity under planktonic growth conditions was increased in the mutant, as was the case for (unprocessed) hydrolases, indicating that the $\sec D F$ deletion did not lead to an overall reduction, but to an altered secretion and processing of proteins. In contrast hemolysin activity was reduced during sessile growth indicating that the deletion of secDF may have effects on overall metabolism.

SpA seemed to be impaired in reaching its destined subcellular localization. In the secDF mutant SpA accumulated in the membrane, was reduced in the cell wall fraction but was found in increased amounts in the supernatant. Altered secretion and processing of SpA might be due to impaired cell wall anchoring by the membrane protein sortase. However, Mazmanian et al. have shown that the extracellular enterotoxin B fused to the sorting signal of SpA accumulates in the cytoplasm and to a lesser extent in the membrane in a sortase mutant [48]. Thus, SpA might migrate by an alternate mechanism into the supernatant, circumventing linking to the peptidoglycan.

A similar divergent effect on protein secretion as we observed in the secDF mutant was found in a secG mutant. There SpA was found in increased amounts in the exoproteome, despite unaffected transcription [11]. In contrast, we found deletion of $\sec D F$ to change mRNA levels for many of the analyzed genes, such as atl, coa, hla, hld and spa. The lack of secDF therefore seems to have a different impact on virulence factor expression than $\sec G$, influencing, most likely indirectly, transcription in addition to translocation. The absence of SecDF could especially cause a defective or reduced membrane insertion of sensor proteins belonging to one of the numerous $S$. aureus two component systems contributing to virulence factor regulation and to adaptations to different growth conditions (reviewed in $[49,50])$. The reduced hld levels in the mutant suggests that the $\sec D F$ deletion affected at least one two component system by impairing signaling via the agr quorum sensor [51].

This study and the work of Sibbald et al. [11] once more demonstrate that protein and mRNA levels do not necessarily correlate. Specific regulation at the protein level has been shown for certain transcription factors in S. aureus $[52,53]$. Such a control of protein stability via chaperones and proteases might exist as well for virulence factors. Interestingly, in $E$. coli, $\sec Y, y i d C$ and secD mutants were shown to induce the Cpx system, which up-regulates the expression of factors involved in folding and proteolysis in response to abnormal proteins in the outer membrane, the periplasmic space or the plasma membrane [54]. The induction of similar systems in the $S$. aureus secDF mutant due to clogging of the membrane, as suggested by the increased amounts of SpA in this compartment, could be an additional factor influencing protein stability and lead to the partially incoherent mRNA and protein levels, as seen for hla, hld and spa during planktonic growth. 


\section{Conclusions}

This work provides evidence that although $\sec D F$ is dispensable in $S$. aureus, its deletion leads to a pleiotropic phenotype. Lack of SecDF affected cell separation, resistance and virulence factor expression showing that this conserved RND protein plays a major role in the important human pathogen $S$. aureus. Thus SecDF could be a potential therapeutic target rendering $S$. aureus more susceptible to the currently available antibiotics.

\section{Methods}

\section{Bacterial strains and growth conditions}

Strains and plasmids used in this study are listed in Table 1 . Bacteria were grown aerobically at $37^{\circ} \mathrm{C}$ in Luria-Bertani broth (LB) (Difco) where not mentioned otherwise. Good aeration for liquid cultures was assured by vigorously shaking flasks with an air-to-liquid ratio of 4 to 1 . Ampicillin $100[\mu \mathrm{g} / \mathrm{ml}]$, anhydrotetracycline 0.2 $[\mu \mathrm{g} / \mathrm{ml}]$, chloramphenicol $10[\mu \mathrm{g} / \mathrm{ml}]$, kanamycin $50[\mu \mathrm{g} /$ $\mathrm{ml}]$ or tetracycline $10[\mu \mathrm{g} / \mathrm{ml}]$ were added to the media when appropriate. Phage $80 \alpha$ alpha was used for transduction. Where nothing else is mentioned, experiments were repeated at least twice and representative data are shown.

\section{Construction of mutants and complementation plasmid} In-frame markerless deletions of sa2056 (NWMN 2'384'867-2'388'051), sa2339 (NWMN 2'696'0462'698'531) and secDF (NWMN 1'706'584-1'708'866) from the chromosome of $S$. aureus Newman (accession number NC_009641) was performed using pKOR1 [23] yielding single mutants CQ33, CQ65 and CQ66, respectively. Correct deletion was confirmed by PCR and by sequencing. Furthermore, strain stability was confirmed by pulsed field gel electrophoresis of total genome SmaI digests [55].

To complement the secDF mutant, secDF with its endogenous promoter was amplified from $S$. aureus strain Newman with primers listed in additional file 2 table S1.

Table 1 Strains and plasmids used in this study

\begin{tabular}{|c|c|c|}
\hline Strain & Relevant genotype or phenotype & Ref. or source \\
\hline \multicolumn{3}{|l|}{ S. aureus } \\
\hline Newman & Clinical isolate (ATCC 25904), rsbU ${ }^{+}$ & {$[64]$} \\
\hline RN4220 & NCTC8325-4 $\mathrm{r}^{-} \mathrm{m}^{+}$ & {$[65]$} \\
\hline CQ33 & Newman $\triangle$ sa2056 & This study \\
\hline CQ39 & Newman pME2, $T c^{r}, M c^{r}$ & This study \\
\hline CQ65 & Newman $\triangle$ sa2339 & This study \\
\hline CQ66 & Newman $\triangle \sec D F$ & This study \\
\hline CQ69 & Newman $\triangle \sec D F$ pME2, $T c^{r}, M c^{r}$ & This study \\
\hline CQ85 & Newman pCN34, $\mathrm{Km}^{\mathrm{r}}$ & This study \\
\hline CQ86 & Newman pCN34 pME2, $\mathrm{Km}^{r}, T c^{r}, M c^{r}$ & This study \\
\hline CQ87 & Newman $\triangle \sec D F$ pCN34, $\mathrm{Km}^{r}$ & This study \\
\hline CQ88 & Newman $\triangle \sec D F$ pCN34 pME2, $\mathrm{Km}^{r}, \mathrm{Tc}^{r}, \mathrm{Mc}^{\mathrm{r}}$ & This study \\
\hline CQ89 & Newman $\triangle \sec D F$ pCQ27, $\mathrm{Km}^{r}$ & This study \\
\hline CQ90 & Newman $\triangle \sec$ F $\mathrm{pCQ} 27 \mathrm{pME2}, \mathrm{Km}^{\mathrm{r}}, \mathrm{T} \mathrm{c}^{\mathrm{r}}, \mathrm{Mc^{r }}$ & This study \\
\hline \multicolumn{3}{|l|}{ E. coli } \\
\hline $\mathrm{DH} 5 \alpha$ & $\begin{array}{l}\text { Cloning strain, [F-Ф80lacZ } \triangle \text { M15 } \triangle(\text { lacZYA-argF)U169 recA1 endA1 hsdR17 (rk-, mk+) phoA supE44 thi-1 gyrA96 relA1 } \\
\lambda \text {-] }\end{array}$ & Invitrogen \\
\hline Plasmid & Relevant genotype or phenotype & $\begin{array}{l}\text { Reference or } \\
\text { source }\end{array}$ \\
\hline $\mathrm{pCN} 34$ & S. aureus-E. coli shuttle vector, pT181-cop-wt repC aphA-3 ColE1 Kmr & {$[56]$} \\
\hline pCQ27 & pCN34 derivative carrying secDF and its promoter (Newman), $\mathrm{Km}^{\mathrm{r}}$ & This study \\
\hline pCQ30 & $\begin{array}{l}\text { pKOR1 derivative carrying } 1 \mathrm{~kb} \text { fragments of the region up- and downstream of sa2056 amplified from Newman, } \\
\text { ligated together with ECORI and recombined at the attP sites, } \mathrm{Ap}^{r}, \mathrm{Cm}^{r}\end{array}$ & This study \\
\hline pCQ31 & $\begin{array}{l}\text { pKOR1 derivative carrying } 1 \mathrm{~kb} \text { fragments of the region up- and downstream of sa2339 amplified from Newman, } \\
\text { ligated together with Hindlll and recombined at the attP sites, } \mathrm{Ap}^{r}, \mathrm{Cm}^{r}\end{array}$ & This study \\
\hline pCQ32 & $\begin{array}{l}\text { pKOR1 derivative carrying } 1 \mathrm{~kb} \text { fragments of the region up- and downstream of secDF amplified from Newman, } \\
\text { ligated together with HindIII and recombined at the attP sites, } \mathrm{Ap}^{r}, \mathrm{Cm}^{r}\end{array}$ & This study \\
\hline pKOR1 & $\begin{array}{l}\text { E. coli-S. aureus shuttle vector used to create markerless deletions; repF(Ts) cat attP ccdB ori ColE1 bla } \mathrm{P}_{x y /} / \text { tetO } \\
\text { secY570, } \mathrm{Ap}^{r}, \mathrm{Cm}^{r}\end{array}$ & {$[23]$} \\
\hline pME2 & pBUS1 derivative carrying mecA and its promoter (COLn), $T C^{r}, M c^{r}$ & {$[28]$} \\
\hline
\end{tabular}


The amplified region was ligated into the SalI/BamHI restriction sites of pCN34, a low copy (20-25 copies/ cell) E. coli-S. aureus shuttle vector [56]. The junction region was sequenced as a control. The resulting plasmid pCQ27 was electroporated into RN4220 with subsequent transduction into the strains of interest.

To construct MRSA strains, the plasmid pME2, containing the mecA promoter and gene from strain COLn [28], was either electroporated or transduced into the strains selected.

Promoter predictions were performed by BPROM http://linux1.softberry.com/berry.phtml. Rho-independent transcriptional terminators were retrieved from the CMR terminator list http://cmr.jcvi.org/tigr-scripts/ CMR/CmrHomePage.cgi.

\section{Transmission electron microscopy (TEM)}

Cells were grown to exponential phase, harvested at $\mathrm{OD}_{600} 0.5$ and fixed for one hour in $2.5 \%$ glutaraldehyde in phosphate buffered saline (PBS) pH 7.4. Electron microscopy was performed by the Center for Microscopy and Image Analysis, University of Zurich.

\section{Resistance profiles}

For qualitative susceptibility comparisons, bacterial suspensions of McFarland 0.5 were swapped across LB agar plates containing antibiotic gradients and incubated at $35^{\circ} \mathrm{C}$ for 20-24 h. Glycopeptides were tested on Brain Heart Infusion (BHI) (Difco) agar with a bacterial suspension of McFarland 2 [57].

\section{Spontaneous and Triton X-100 induced autolysis}

Cells were grown to an $\mathrm{OD}_{600}$ of 0.7 , pelleted by centrifugation and washed with $0.85 \% \mathrm{NaCl}$. The cells were then resuspended in $0.01 \mathrm{M} \mathrm{Na}$-phosphate buffer $\mathrm{pH} 7$ and the $\mathrm{OD}_{600}$ was adjusted to 0.7. After splitting the cultures, $0.01 \%$ Triton X-100 (Fluka) or an equal volume of PBS pH 7 was added. Cultures were incubated at $37^{\circ}$ $\mathrm{C}$ and the decrease of $\mathrm{OD}_{600}$ was measured.

\section{Zymographic analyses}

Cultures were grown to an $\mathrm{OD}_{600}=0.7$, centrifuged and the filtered supernatants (pore size $0.45 \mu \mathrm{m}$, TPP) stored at $-20^{\circ} \mathrm{C}$ until further use. The cell wall peptidoglycan was digested in SMM buffer (0.5 M sucrose, $0.02 \mathrm{M}$ maleate, $0.02 \mathrm{MgCl}_{2} \mathrm{pH}$ 6.5) supplemented with $72 \mu \mathrm{g} /$ $\mathrm{ml}$ lysostaphin and $2 \mathrm{mM}$ phenylmethylsulfonyl fluoride (PMSF) [38]. Cell wall containing supernatant was separated from the protoplasts and stored at $-20^{\circ} \mathrm{C}$ until further use. Protein concentrations were measured by Bradford assay (BioRad).

Twenty $\mu \mathrm{g}$ of protein from each fraction was separated by SDS-10\% polyacrylamide gel electrophoresis (PAGE) containing cell wall extract of heat-inactivated
(1 hour at $100^{\circ} \mathrm{C}$ in $4 \%$ SDS) S. aureus (end concentration $\mathrm{OD}_{600}=6$ ). The gel was washed twice for $15 \mathrm{~min}$ in $\mathrm{dH}_{2} \mathrm{O}$ and incubated for $18 \mathrm{~h}$ at $37^{\circ} \mathrm{C}$ in $0.1 \mathrm{M} \mathrm{Na}$ phosphate buffer $\mathrm{pH}$ 6.8. Afterwards the gel was incubated for $3 \mathrm{~min}$ in staining solution $(0.4 \%$ methylene blue, $0.01 \% \mathrm{KOH}, 22 \% \mathrm{EtOH}$ ) and destained in cold water for several hours. Murein hydrolase activities produced clear bands.

\section{Coagulase test}

Overnight cultures were pelleted at full speed, $0.5 \mathrm{ml}$ supernatant was transferred into fresh tubes and $2 \mathrm{mM}$ PMSF was added. The supernatants were normalized to an $\mathrm{OD}_{600}$ of 1 of the original culture with PBS. $0.1 \mathrm{ml}$ supernatant was added to $0.25 \mathrm{ml}$ reconstituted rabbit plasma (BBL Coagulase Plasmas, BD) and incubated at $37^{\circ} \mathrm{C}$. Every $30 \mathrm{~min}$ tubes were examined for coagulation.

\section{Qualitative hemolysis assay}

Cells were grown overnight in Todd-Hewitt (TH) medium [58], which was originally developed for the production of streptococcal hemolysins [59]. To visualize hemolysis production of sessile bacteria, overnight cultures were normalized to an $\mathrm{OD}_{600}=1$ in PBS pH 7.4. Fifty $\mu \mathrm{l}$ was dispensed into $5 \mathrm{~mm}$ wide holes punched into $5 \%$ sheep blood agar. Plates were incubated overnight at $37^{\circ} \mathrm{C}$ and then stored at $4{ }^{\circ} \mathrm{C}$. To determine hemolysis in liquid media, the overnight cultures grown in $\mathrm{TH}$ medium were normalized to the same $\mathrm{OD}_{600}$ with PBS and pelleted for $10 \mathrm{~min}$ at 5'900 g. The supernatant was filtered (pore size $0.22 \mu \mathrm{m}, \mathrm{TPP}$ ) and $140 \mu \mathrm{l}$ added to the holes in sheep blood agar. Plates were incubated as above.

\section{Quantitative hemolytic activity}

Cells were grown for $24 \mathrm{~h}$ in $\mathrm{TH}$ medium and normalized with PBS pH 7.4 to the same $\mathrm{OD}_{600}$. After pelleting the cells, the filtered supernatants (pore size $0.22 \mu \mathrm{m}$, TPP) were diluted up to 1:50'000 in TH medium. Sterile sheep blood was treated with $26 \mathrm{mM}$ sodium citrate and $15 \mathrm{mM} \mathrm{NaCl}$ and diluted 1:100 in PBS pH 7.4. After washing the erythrocytes four times in PBS pH 7.4, they were resuspended to a dilution of 1:100 in PBS pH 7.4. Five hundred $\mu \mathrm{l}$ of washed erythrocytes were added to $500 \mu \mathrm{l}$ of the diluted supernatants and incubated for 30 min at $37^{\circ} \mathrm{C}$, followed by $30 \mathrm{~min}$ at $4^{\circ} \mathrm{C}$. Finally the samples were centrifuged for $1 \mathrm{~min}$ at 7'000 g and the absorption of hemoglobin in the supernatant was measured at $415 \mathrm{~nm}$ [58].

\section{Determination of protease activity on skim milk agar plates}

Skim milk agar plates were prepared as follows: Skim milk (Difco) and Bacto agar (Difco) were dissolved 


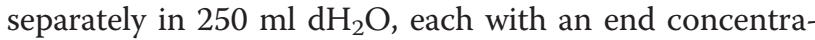
tion of $75 \mathrm{~g} / \mathrm{l}$ and $15 \mathrm{~g} / \mathrm{l}$, respectively. After autoclaving for $15 \mathrm{~min}$ at $110^{\circ} \mathrm{C}$ and cooling down to $50^{\circ} \mathrm{C}$, the skim milk and Bacto agar solutions were mixed together. Overnight cultures grown in LB broth were normalized to an $\mathrm{OD}_{600}=1$ with $0.85 \% \mathrm{NaCl}$ and $50 \mu \mathrm{l}$ was added into punched holes in skim milk agar. Skim milk agar plates were incubated at $37^{\circ} \mathrm{C}$ for $24 \mathrm{~h}$ and another $96 \mathrm{~h}$ at room temperature.

\section{Transcription analyses}

Prewarmed LB broth was inoculated with an overnight culture to an $\mathrm{OD}_{600} 0.05$ and incubated at $37^{\circ} \mathrm{C}$. Cells were harvested at $\mathrm{OD}_{600} 0.2,0.5,1,3$ and 6 , centrifuged for $5 \mathrm{~min}$ at $20^{\prime} 000 \mathrm{~g}$ and $4^{\circ} \mathrm{C}$. Cells were immediately snap frozen in liquid nitrogen and stored at $-80^{\circ} \mathrm{C}$. Total RNA was extracted as described in [60]. Seven $\mu \mathrm{g}$ RNA was separated in a $1.5 \%$ agarose gel containing $20 \mathrm{mM}$ guanidine thiocyanate in $1 \times$ TBE [61]. RNA was transferred onto a positively charged nylon membrane (Roche) using the downward capillary transfer method. The blots were hybridized with specific digoxigenin (DIG)-labeled DNA probes (Roche). Primers used are listed in Additional file 2 Table S1.

\section{Analyses of subcellular protein fractions}

Cells were sampled as described for transcription analyses and culture supernatant was collected as described for zymographic analysis. Cells were fractionated basically according to Schneewind et al. [38]. Briefly, cells were digested in SMM buffer supplemented with each $72 \mu \mathrm{g} / \mathrm{ml}$ lysostaphin and lysozyme, $36 \mu \mathrm{g} / \mathrm{ml}$ DNase and $2 \mathrm{mM}$ PMSF. Protoplasts were separated from the cell wall containing supernatant by centrifugation for 4 $\mathrm{min}$ at $16^{\prime} 000 \mathrm{~g}$. Protoplasts were resuspended in membrane buffer $\left(0.1 \mathrm{M} \mathrm{NaCl}, 0.1 \mathrm{M}\right.$ Tris- $\mathrm{HCl}, 0.01 \mathrm{MgCl}_{2}$ $\mathrm{pH} 7.5$ ) and lysed by three cycles of freezing in liquid nitrogen/thawing at $20^{\circ} \mathrm{C}$. Cell membranes were separated from the cytoplasm by centrifugation for $30 \mathrm{~min}$ at $20^{\prime} 000 \mathrm{~g}$ and $4^{\circ} \mathrm{C}$. Membrane pellets were solubilized in buffer B (25 mM Tris- $\mathrm{HCl}$ pH 7.5, $150 \mathrm{mM} \mathrm{NaCl}, 1$ $\mathrm{mM} \mathrm{MgCl} 2,30 \%$ glycerol) supplemented with $1 \%$ Triton $\mathrm{X}-100$ and $0.5 \% \mathrm{~N}$-lauroylsarcosine, by gently mixing end-over-end at $4{ }^{\circ} \mathrm{C}$. Where necessary, protein fractions were concentrated with Amicon Ultra-15, -4 or -0.5 centrifugal filter units (MWCO $10 \mathrm{kDa}$, Millipore). Cell fractions were kept at $-20^{\circ} \mathrm{C}$.

Five $\mu \mathrm{g}$ of protein was separated by SDS-10\% PAGEs and either stained with Coomassie Imperial ${ }^{\mathrm{TM}}$ Protein Stain (Thermo Scientific) or blotted onto a PVDF-membrane (Immobilon-P, Millipore). For detection of SpA, membranes were blocked with $5 \%$ milk powder in PBS and then incubated with goat anti-human IgA conjugated with horseradish peroxidase (HRP, Sigma-Aldrich),
$1: 10^{\prime} 000$ in $0.5 \%$ milk powder/PBS, $0.05 \%$ Tween 20 (AppliChem). After washing three times with PBS pH 7.4, HRP was detected with SuperSignal West Pico Chemiluminescent substrate (Thermo Scientific). PBP2a was detected as described in [28]. For detection of PBP4, membranes were blocked with $5 \%$ milk powder in PBS. Membranes were pre-incubated with $40 \mu \mathrm{g} / \mathrm{ml}$ human IgG in $0.5 \%$ milk powder/PBS. Rabbit anti-PBP4 antibodies (1:2000, [62]) and $0.05 \%$ Tween 20 were then added. After incubation for $1 \mathrm{~h}$, membranes were washed three times with PBS before addition of goat anti-rabbit IgGHRP (Jackson ImmunoResearch), 1:10'000 in 0.5\% milk powder/PBS/0.05\% Tween 20. After washing three times with PBS, HRP was detected as described for SpA. Molecular weights of PBP2a, PBP4 and unprocessed SpA are $76 \mathrm{kDa}, 48 \mathrm{kDa}$ and $56.7 \mathrm{kDa}$, respectively.

\section{Bocillin-FL staining}

Hundert $\mu \mathrm{g}$ of cell membrane fraction were incubated for $30 \mathrm{~min}$ at $35^{\circ} \mathrm{C}$ with Bocillin-FL (Invitrogen) as described by [63] before separation by SDS-7.5\% PAGE. Fluorescence was visualized with the FluorChem ${ }^{\mathrm{TM}} \mathrm{SP}$ imaging system (AlphaInnotech).

\section{Additional material}

Additional file 1: Figure S1 - SpA processing in strain Newman Western blot analyses of (A) subcellular fractions of wild type grown to an $\mathrm{OD}_{600}$ of 3 and (B) of total extract from overnight cultures of wild type and spa mutant using goat anti-human IgA antibodies. Coomassie stained total protein is shown on the right as an indication of loading. SN, supernatant; CW, cell wall; CM, cell membrane; CP, cytoplasm.

Additional file 2: Table S1 - Primers used in this study.

\section{Acknowledgements}

We thank S. Burger for her technical help. We are thankful to U. Luethy (Center for Microscopy and Image Analysis, University of Zurich) for TEM analysis. We are grateful to Hitoshi Komatsuzawa for kindly donating the rabbit anti PBP4 antibodies.

This study was supported by the Swiss National Science Foundation grant 31-117707 to B. Berger-Bächi, the Gottfried und Julia Bangerter-Rhyner Stiftung as well as the Olga Mayenfisch Stiftung to C. Quiblier, and the Stiftung für Forschung an der Medizinischen Fakultät der Universität Zürich to A. S. Zinkernagel.

\section{Author details}

${ }^{1}$ Institute of Medical Microbiology, University of Zurich, Gloriastr. 32, 8006 Zurich, Switzerland. 'Division of Infectious Diseases and Hospital

Epidemiology, University Hospital Zurich, University of Zurich, Raemistr. 100, 8091 Zurich, Switzerland. ${ }^{3}$ Surgical Intensive Care, University Hospital Zurich, University of Zurich, Raemistr. 100, 8091 Zurich, Switzerland.

\section{Authors' contributions}

CQ carried out construction of strains, phenotypic characterizations, transcription analysis and drafted the manuscript. ASZ and RAS contributed to the growth condition experiments and participated in writing of the manuscript. MMS carried out the Western blot analyses, Bocillin-FL staining and participated in writing the manuscript. BBB coordinated the study and participated in writing of the manuscript. All authors read and approved the final manuscript. 
Received: 20 January 2011 Accepted: 12 April 2011

Published: 12 April 2011

\section{References}

1. Sibbald MJJB, Ziebandt AK, Engelmann S, Hecker M, de Jong A Harmsen HJM, Raangs GC, Stokroos I, Arends JP, Dubois JYF, et al: Mapping the pathways to staphylococcal pathogenesis by comparative secretomics. Microbiol Mol Biol Rev 2006, 70(3):755-788.

2. Driessen AJM, Nouwen N: Protein translocation across the bacterial cytoplasmic membrane. Annu Rev Biochem 2008, 77(1):643-667.

3. Pogliano JA, Beckwith J: SecD and SecF facilitate protein export in Escherichia coli. EMBO J 1994, 13:554-561.

4. Duong F, Wickner W: The SecDFyajC domain of preprotein translocase controls preprotein movement by regulating SecA membrane cycling. EMBO J 1997, 16(16):4871-4879.

5. Nouwen N, Piwowarek M, Berrelkamp G, Driessen AJM: The large first periplasmic loop of SecD and SecF plays an important role in SecDF functioning. J Bacteriol 2005, 187(16):5857-5860.

6. Gardel C, Benson S, Hunt J, Michaelis S, Beckwith J: $\sec D$, a new gene involved in protein export in Escherichia coli. J Bacteriol 1987, 169(3):1286-1290.

7. Pogliano KJ, Beckwith J: Genetic and molecular characterization of the Escherichia coli secD operon and its products. J Bacteriol 1994, 176(3):804-814

8. Duong F, Wickner W: Distinct catalytic roles of the SecYE, SecG and SecDFyajC subunits of preprotein translocase holoenzyme. EMBO J 1997, 16(10):2756-2768.

9. Nouwen N, Driessen AJM: SecDFyajC forms a heterotetrameric complex with YidC. Mol Microbiol 2002, 44(5):1397-1405.

10. Ji Y, Zhang B, Van SF, Warren P, Woodnutt G, Burnham MKR, Rosenberg M: Identification of critical staphylococcal genes using conditional phenotypes generated by antisense RNA. Science 2001, 293(5538):2266-2269.

11. Sibbald MJJB, Winter T, van der Kooi-Pol MM, Buist G, Tsompanidou E, Bosma T, Schafer T, Ohlsen K, Hecker M, Antelmann H, et al: Synthetic effects of sec $G$ and sec $Y 2$ mutations on exoproteome biogenesis in Staphylococcus aureus. J Bacteriol 2010, 192(14):3788-3800.

12. Siboo IR, Chaffin DO, Rubens CE, Sullam PM: Characterization of the accessory Sec system of Staphylococcus aureus. J Bacteriol 2008, 190(18):6188-6196.

13. Lee E-Y, Choi D-Y, Kim D-K, Kim J-W, Park JO, Kim S, Kim S-H, Desiderio DM, Kim Y-K, Kim K-P, et al: Gram-positive bacteria produce membrane vesicles: Proteomics-based characterization of Staphylococcus aureusderived membrane vesicles. Proteomics 2009, 9(24):5425-5436.

14. Solis N, Larsen MR, Cordwell SJ: Improved accuracy of cell surface shaving proteomics in Staphylococcus aureus using a false-positive control. PROTEOMICS 2010, 10(10):2037-2049.

15. Hempel K, Pané-Farré J, Otto A, Sievers S, Hecker M, Becher D: Quantitative cell surface proteome profiling for SigB-dependent protein expression in the human pathogen Staphylococcus aureus via biotinylation approach. $J$ Proteome Res 2010, 9(3):1579-1590.

16. Chaudhuri R, Allen A, Owen P, Shalom G, Stone K, Harrison M, Burgis T, Lockyer M, Garcia-Lara J, Foster S, et al: Comprehensive identification of essential Staphylococcus aureus genes using transposon-mediated differential hybridisation (TMDH). BMC Genomics 2009, 10(1):291.

17. Tseng TT, Gratwick KS, Kollman J, Park D, Nies DH, Goffeau A, Saier MH Jr: The RND permease superfamily: An ancient, ubiquitous and diverse family that includes human disease and development proteins. $J \mathrm{Mol}$ Microbiol Biotechnol 1999, 1(1):107-125.

18. Thanassi DG, Cheng LW, Nikaido H: Active efflux of bile salts by Escherichia coli. J Bacteriol 1997, 179(8):2512-2518.

19. Davies JP, Chen FW, loannou YA: Transmembrane molecular pump activity of Niemann-Pick C1 protein. Science 2000, 290(5500):2295-2298

20. Takatsuka Y, Chen C, Nikaido H: Mechanism of recognition of compounds of diverse structures by the multidrug efflux pump AcrB of Escherichia coli. Proc Natl Acad Sci USA 2010, 107(15):6559-6565.

21. Nikaido $\mathrm{H}$ : Multidrug efflux pumps of Gram-negative bacteria. J Bacteriol 1996, 178(20):5853-5859.

22. Rohrer S, Ehlert K, Tschierske M, Labischinski H, Berger-Bächi B: The essential Staphylococcus aureus gene $\mathrm{fmhB}$ is involved in the first step of peptidoglycan pentaglycine interpeptide formation. PNAS 1999 96(16):9351-9356.

23. Bae T, Schneewind O: Allelic replacement in Staphylococcus aureus with inducible counter-selection. Plasmid 2006, 55(1):58-63.

24. Bolhuis A, Broekhuizen CP, Sorokin A, van Roosmalen ML, Venema G, Bron S, Quax WJ, van Dijl JM: SecDF of Bacillus subtilis, a molecular siamese twin required for the efficient secretion of proteins. J Biol Chem 1998, 273(33):21217-21224.

25. Poole K: Efflux-mediated antimicrobial resistance. J Antimicrob Chemother 2005, 56(1):20-51.

26. Tsuge $K$, Ohata $Y$, Shoda M: Gene yerP, involved in surfactin selfresistance in Bacillus subtilis. Antimicrob Agents Chemother 2001, 45(12):3566-3573.

27. Piddock LJ: Multidrug-resistance efflux pumps - not just for resistance. Nat Rev Microbiol 2006, 4(8):629-636.

28. Ender M, McCallum N, Berger-Bächi B: Impact of mecA promoter mutations on mecA expression and $\beta$-lactam resistance levels. Int $\mathrm{J}$ Med Microbiol 2008, 298(7-8):607-617.

29. Ender M: Molecular and functional characterisation of the Swiss drug clone, a methicillin-resistant Staphylococcus aureus. Dissertation University of Zurich 2008

30. Lee SM, Ender M, Adhikari R, Smith JM, Berger-Bachi B, Cook GM: Fitness cost of staphylococcal cassette chromosome mec in methicillin-resistant Staphylococcus aureus by way of continuous culture. Antimicrob Agents Chemother 2007, 51(4):1497-1499.

31. Ender M, McCallum N, Adhikari R, Berger-Bachi B: Fitness cost of SCCmec and methicillin resistance levels in Staphylococcus aureus. Antimicrob Agents Chemother 2004, 48(6):2295-2297.

32. Pereira SFF, Henriques $A O$, Pinho $M G$, de Lencastre $H$, Tomasz $A$ : Role of PBP1 in cell division of Staphylococcus aureus. J Bacteriol 2007, 189(9):3525-3531.

33. Pinho MG, Ludovice AM, Wu S, De Lencastre $\mathrm{H}$ : Massive reduction in methicillin resistance by transposon inactivation of the normal PBP2 in a methicillin-resistant strain of Staphylococcus aureus. Microb Drug Resist 1997, 3(4):409-413.

34. Zhao G, Meier TI, Kahl SD, Gee KR, Blaszczak LC: BOCILLIN FL, a sensitive and commercially available reagent for detection of penicillin-binding proteins. Antimicrob Agents Chemother 1999, 43(5):1124-1128.

35. Schlag M, Biswas R, Krismer B, Kohler T, Zoll S, Yu W, Schwarz H, Peschel A, Götz F: Role of staphylococcal wall teichoic acid in targeting the major autolysin Atl. Mol Microbiol 2010, 75(4):864-873.

36. Lindsay JA, Foster SJ: Interactive regulatory pathways control virulence determinant production and stability in response to environmental conditions in Staphylococcus aureus. Mol Gen Genet 1999, 262(2):323-331.

37. Cheung $A L$, Fischetti VA: Variation in the expression of cell wall proteins of Staphylococcus aureus grown on solid and liquid media. Infect Immun 1988, 56(5):1061-1065.

38. Schneewind O, Mihaylova-Petkov D, Model P: Cell wall sorting signals in surface proteins of gram-positive bacteria. Embo J 1993, 12(12):4803-4811.

39. Baba T, Bae T, Schneewind O, Takeuchi F, Hiramatsu K: Genome sequence of Staphylococcus aureus strain Newman and comparative analysis of staphylococcal genomes: Polymorphism and evolution of two major pathogenicity islands. J Bacterio/ 2008, 190(1):300-310.

40. Clyne M, Birkbeck TH, Arbuthnott JP: Characterization of staphylococcal Ylysin. J Gen Microbiol 1992, 138(5):923-930.

41. Li XZ, Nikaido H: Efflux-mediated drug resistance in bacteria: an update. Drugs 2009, 69(12):1555-1623

42. Banerjee R, Gretes M, Harlem C, Basuino L, Chambers HF: A mecA-negative strain of methicillin-resistant Staphylococcus aureus with high-level $\beta$ lactam resistance contains mutations in three genes. Antimicrob Agents Chemother 2010, 54(11):4900-4902.

43. Pinho MG, Errington J: Dispersed mode of Staphylococcus aureus cell wall synthesis in the absence of the division machinery. Mol Microbiol 2003, 50(3):871-881.

44. Antignac A, Sieradzki K, Tomasz A: Perturbation of cell wall synthesis suppresses autolysis in Staphylococcus aureus: Evidence for coregulation of cell wall synthetic and hydrolytic enzymes. J Bacteriol 2007, 189(21):7573-7580.

45. Chauhan A, Lofton H, Maloney E, Moore J, Fol M, Madiraju MWS, Rajagopalan M: Interference of Mycobacterium tuberculosis cell division by Rv2719c, a cell wall hydrolase. Mol Microbiol 2006, 62(1):132-147. 
46. Margolin W: Sculpting the bacterial cell. Curr Biol 2009, 19(17):R812-R822.

47. Arkowitz RA, Wickner W: SecD and SecF are required for the proton electrochemical gradient stimulation of preprotein translocation. EMBO J 1994, 13(4):954-963.

48. Mazmanian SK, Liu G, Jensen ER, Lenoy E, Schneewind O: Staphylococcus aureus sortase mutants defective in the display of surface proteins and in the pathogenesis of animal infections. Proc Natl Acad Sci USA 2000, 97(10):5510-5515.

49. Novick RP: Autoinduction and signal transduction in the regulation of staphylococcal virulence. Mol Microbiol 2003, 48(6):1429-1449.

50. Cheung AL, Bayer AS, Zhang G, Gresham H, Xiong Y-Q: Regulation of virulence determinants in vitro and in vivo in Staphylococcus aureus. FEMS Immunol Med Microbiol 2004, 40(1):1-9.

51. Lina G, Jarraud S, Ji G, Greenland T, Pedraza A, Etienne J, Novick RP, Vandenesch F: Transmembrane topology and histidine protein kinase activity of AgrC, the agr signal receptor in Staphylococcus aureus. Mol Microbiol 1998, 28(3):655-662.

52. Frees $\mathrm{D}$, Sorensen $\mathrm{K}$, Ingmer $\mathrm{H}$ : Global virulence regulation in Staphylococcus aureus: Pinpointing the roles of ClpP and ClpX in the sar/ agr regulatory network. Infect Immun 2005, 73(12):8100-8108.

53. Michel A, Agerer F, Hauck CR, Herrmann M, Ullrich J, Hacker J, Ohlsen K: Global regulatory impact of ClpP protease of Staphylococcus aureus on regulons involved in virulence, oxidative stress response, autolysis, and DNA repair. J Bacteriol 2006, 188(16):5783-5796.

54. Shimohata N, Nagamori S, Akiyama Y, Kaback HR, Ito K: SecY alterations that impair membrane protein folding and generate a membrane stress. J Cell Biol 2007, 176(3):307-317.

55. Wada A, Katayama Y, Hiramatsu K, Yokota T: Southern hybridization analysis of the mecA deletion from methicillin-resistant Staphylococcus aureus. Biochem Biophys Res Commun 1991, 176(3):1319-1325.

56. Charpentier E, Anton Al, Barry P, Alfonso B, Fang Y, Novick RP: Novel cassette-based shuttle vector system for Gram-positive bacteria. Appl Environ Microbiol 2004, 70(10):6076-6085.

57. Walsh TR, Bolmstrom A, Qwarnstrom A, Ho P, Wootton M, Howe RA, MacGowan AP, Diekema D: Evaluation of current methods for detection of staphylococci with reduced susceptibility to glycopeptides. J Clin Microbiol 2001, 39(7):2439-2444

58. Nilsson I-M, Hartford O, Foster T, Tarkowski A: Alpha-toxin and gammatoxin jointly promote Staphylococcus aureus virulence in murine septic arthritis. Infect Immun 1999, 67(3):1045-1049.

59. Todd EW, Hewitt LF: A new culture medium for the production of antigenic streptococcal haemolysin. J Pathol Bacteriol 1932, 35(6):973-974.

60. Cheung AL, Eberhardt KJ, Fischetti VA: A method to isolate RNA from gram-positive bacteria and mycobacteria. Anal Biochem 1994, 222(2):511-514.

61. Goda SK, Minton NP: A simple procedure for gel electrophoresis and Northern blotting of RNA. Nucl Acids Res 1995, 23(16):3357-3358.

62. Komatsuzawa H, Ohta K, Yamada S, Ehlert K, Labischinski H, Kajimura J, Fujiwara T, Sugai M: Increased glycan chain length distribution and decreased susceptibility to moenomycin in a vancomycin-resistant Staphylococcus aureus mutant. Antimicrob Agents Chemother 2002, 46(1):75-81.

63. Gee KR, Kang HC, Meier TI, Zhao G, Blaszcak LC: Fluorescent Bocillins: Synthesis and application in the detection of penicillin-binding proteins. Electrophoresis 2001, 22(5):960-965.

64. Duthie ES, Lorenz LL: Staphylococcal coagulase: Mode of action and antigenicity. J Gen Microbiol 1952, 6(1-2):95-107.

65. Kreiswirth BN, Lofdahl S, Betley MJ, O'Reilly M, Schlievert PM, Bergdoll MS, Novick RP: The toxic shock syndrome exotoxin structural gene is not detectably transmitted by a prophage. Nature 1983, 305(5936):709-712.

doi:10.1186/1471-2180-11-72

Cite this article as: Quiblier et al:: Contribution of SecDF to Staphylococcus aureus resistance and expression of virulence factors. BMC Microbiology 2011 11:72.

\section{Submit your next manuscript to BioMed Central and take full advantage of:}

- Convenient online submission

- Thorough peer review

- No space constraints or color figure charges

- Immediate publication on acceptance

- Inclusion in PubMed, CAS, Scopus and Google Scholar

- Research which is freely available for redistribution

Submit your manuscript at www.biomedcentral.com/submit
C Biomed Central 